\title{
Prevalence and antimicrobial resistance of Staphylococcus species isolated from cats and dogs
}

\author{
Hiam R. Elnageh ${ }^{1}$, Murad A. Hiblu², Mohamed Salah Abbassi ${ }^{3}$, Yousef M. Abouzeed ${ }^{1}$ and Mohamed O. Ahmed ${ }^{1 *}$ \\ ${ }^{1}$ Department of Microbiology and Parasitology, Faculty of Veterinary Medicine, University of Tripoli, Tripoli, Libya \\ ${ }^{2}$ Department of Internal Medicine, Faculty of Veterinary Medicine, University of Tripoli, Tripoli, Libya \\ ${ }^{3}$ University of Tunis El Manar, Institute of Veterinary Research of Tunisia, Tunis, Tunisia
}

\begin{abstract}
Background: Methicillin-resistant staphylococci (MRS) are an emerging global problem with serious public health concern.

Aims: This study investigated the prevalence and antimicrobial susceptibility of commensal Staphylococcus species isolated from healthy and clinical cats and dogs.

Methods: Nasal swab samples were collected from animals and processed using selective and semi-selective mediums. Presumptive isolates were subjected to biochemical testing and analyzed using the Phoenix automated identification and susceptibility testing system. PCRs protocols were used to screen for $m e c A$ and pvl genes.

Results: In total, 151 pets (103 cats and 48 dogs) were enrolled, of which 14 dogs $(29 \%)$ and 24 cats (23\%) were colonized with various Staphylococcus species mainly originated from healthy animals. A total of 38 staphylococci isolates were collected and distributed between 24 coagulase-negative and 14 coagulase-positive staphylococci. Only 13 staphylococci strains were identified as MRS, out of which only five isolates expressed that the mecA gene exclusively originated from healthy pets.

Conclusion: This is the first study reporting the prevalence and colonization status of staphylococci species and MRS strains isolated from cats and dogs in Libya. The study reports important information of medical and clinical importance on antimicrobial and multidrug resistance of different staphylococci strains, particularly the coagulase negative species.
\end{abstract}

Keywords: Coagulase-negative staphylococci, Libya, mecA gene, pet animals, Staphylococcus.

\section{Introduction}

Staphylococcus species are classic commensals bacteria of the skin and mucous membranes of mammals and birds (Grice and Segre, 2011). Staphylococcus aureus is the main pathogenic species; however, other staphylococci emerged, particularly the coagulasenegative staphylococci (CoNS), causing serious opportunistic infections in human and animals (Rich, 2005). In Africa, the incidence of CoNS varied across the continent and reported approximately from $68 \%$ and $62 \%$ of suspected human and animal infections, respectively, particularly from clinical cattle and hospitalized humans (Asante et al., 2020). In Libya, methicillin-resistant $S$. aureus (MRSA) is the most reported and investigated nosocomial pathogens exclusively isolated from healthcare settings and human clinical sources (Ahmed et al., 2017).

Cats and dogs can be colonized with various staphylococci species causing opportunistic infections and outbreaks (e.g., S. aureus, Staphylococcus lentus, Staphylococcus schleiferi, and Staphylococcus pseudintermedius) (van Duijkeren et al., 2011; Gandolfi-Decristophoris et al., 2013; Harrison et al., 2014; Ma et al., 2020). Methicillin-resistant staphylococci (MRS) were isolated from household pets associated significantly with antibiotic intake and veterinary hospitalization, expressing genetic determinants and clonal lineages similar to those typically identified in humans and other animals (i.e., staphylococcal cassette chromosome and PantonValentine Leucocidin ( $p v l)$ gene) (van Duijkeren et al., 2005; Han et al., 2016; Rossi et al., 2017; Loncaric et al., 2019). Nevertheless, epidemiological and clinical information from Africa on healthcare-associated pathogens isolated from pet animals are very rare compared to the extensive knowledge on human and food-producing animals (Ahmed and Baptiste, 2018; Asante et al., 2020). The aim of the current study was to investigate the prevalence and antimicrobial susceptibility of Staphylococcus species isolated from healthy and clinical cats and dogs in Tripoli, Libya.

\section{Criteria of sampling}

\section{Material and Methods}

The present study included household cats and dogs that were clinically healthy and showed no signs 
of systemic diseases, and were not being under any medication, including antimicrobials use for at least 3 months prior to enrolment in this study, and was referred to as the "healthy group". The study also included clinical cats and dogs with gastrointestinal infections treated with antimicrobial therapy (i.e., penicillins, amoxicillin, enrofloxacin, gentamicin, and trimethoprim-sulfamethoxazole), and was referred to as the "clinical group". Duplicate nasal swap samples were obtained from both nostrils of each animal using sterile, moist cotton swabs and transferred to the laboratory for isolation and characterization within 2-4 hours. Owners of animals were informed about the purpose of the study and were asked for their consent.

Isolation and molecular analysis of Staphylococcus spp. Nasal samples of each animal were, respectively, cultured onto mannitol salt and Columbia blood agars and incubated at $35^{\circ} \mathrm{C}$ for 24 hours. A typical growing colony was selected from each plate and subjected to Gram-stain, catalase test, and coagulase reactivity. For the purpose of this study, only one presumptive isolate was selected to represent each sample and subjected for further testing. Presumptive isolates were further tested by the automated identification and susceptibility testing system BD Phoenix (PAMS, MSBD Biosciences, Sparks Md, USA) to identify and confirm the species of each isolate, and for the determination of susceptibility to antimicrobial agents. Confirmed staphylococci species were further screened for important genetic determinants frequently reported from healthcare-associated bacterial organisms using PCR-adopted protocols for methicillin encoding mecA lukS/lukF genes encoding Panton-Valentine leucocidin (PVL) (Frebourg et al., 2000; Jarraud et al., 2002).

\section{Statistical analysis}

The analysis of positive samples was carried out using Epi Info $^{\mathrm{TM}}$ of the Center for Disease Control and Prevention using the chi-square test at $p \leq 0.05$.

\section{Ethical approval}

This study obtained approval from the Department of Microbiology and Parasitology, Faculty of Veterinary Medicine, University of Tripoli, Libya.

\section{Results}

A total of 151 pets were involved in the study, including 103 cats (62 healthy and 41 clinical) and 48 dogs (37 healthy and 11 clinical). Of these, 38/151 (25\%) carried various Staphylococcus species distributed between $23 \%(24 / 103)$ of cat samples (23 from healthy and 1 from clinical) and 29\% (14/48) of dog samples (10 from healthy and 4 from clinical). Healthy cats were significantly higher carrier of staphylococci than healthy dogs $(p<0.05) ; 37 \%$ of healthy cats $(n=$ $23 / 62)$ compared with $26 \%$ of healthy dogs $(n=10 / 37)$. Furthermore, there were no significant differences of CoNS, CoPS, and mecA-MRSA carriage between cats and dogs $(p>0.05)$.
A total of 38 confirmed staphylococci isolates were collected, characterized, and distributed between $24(63 \%)$ coagulase-negative $(\mathrm{CoN})$ and $14(37 \%)$ coagulase-positive (CoP) staphylococci. Staphylococcus felis $(n=12 ; 31 \%)$ was the most identified CoNS, followed by $S$. sciuri group (including $S$. lentus) $(\mathrm{n}=$ 9; 21\%), S. capitis $(\mathrm{n}=2 ; 5 \%)$, and S. cohnii $(n=1$; $3 \%)$. S. aureus $(n=8 ; 21 \%)$ was the most identified CoPS, followed by $S$. intermedius $(n=5 ; 13 \%)$ and S. schleiferi $(n=1 ; 3 \%)$ (Table 1). S. felis, S. intermedius, $S$. capitis, S. schleiferi, and $S$. cohnii isolates were exclusively of cat origins, whereas $S$. sciuri isolates were exclusively from dogs, but $S$. aureus isolates were isolated from both animals. The collection expressed high resistances to penicillins, followed by amoxicillinclavulanate, cephalosporins (cefoxitin and cefotaxime), and very low resistance to gentamicin, trimethoprimsulfamethoxazole, and ciprofloxacin. Three isolates expressed resistance to clindamycin, of which a single $S$. lentus isolate was also resistant to erythromycin and characterized as macrolide-lincosamide-streptogramin B resistance $\left(\mathrm{MLS}_{\mathrm{B}}\right)$ resistance phenotype, originated from a clinical dog. Resistance to mupirocin was not detected (Table 2).

The Phoenix automated system characterized 34\% $(13 / 38)$ of isolates expressing methicillin resistance phenotype distributed over 11 CoNS $[S$. sciuri $(n=$ 8), S. capitis $(n=1)$, S. cohnii $(n=1)$, S. lentus $(n=$ $1)$ ] and two $S$. aureus isolates. PCRs confirmed 13\% $(5 / 38)$ of isolates positive for the mecA gene (S. aureus, S. intermedius, S. cohnii, S. capitis, and S. sciuri) originated from healthy pets mostly of cat origins. All these mecA-MRS strains were also characterized by the Phoenix system as MRS, except a $S$. intermedius isolate. The $p v l$ gene was not identified.

\section{Discussion}

Cats and dogs are frequently colonized by various staphylococci showing variable dynamics (Davis et al., 2014; Ruzauskas et al., 2015; Kaspar et al., 2018). A recent study reported a high colonization rate of diverse staphylococci species among cats and dogs, particularly with CoNS (i.e., 20 different species), and significantly higher in dogs than cats (Ma et al., 2020). On the contrary, the current study revealed that cats were highly colonized with six diverse staphylococci species, particularly of the CoNS group (i.e., three different species) representing also $63 \%$ of the collected isolates mostly from healthy pets. The very low colonization rate of staphylococci and absence of MRS strains from clinical animals in the current study might be related to the sample size and/or attributed to the ability of staphylococci to persist throughout atypical environmental conditions, including antimicrobial therapies.

MRS are a major global and health concerns increasingly reported from humans and animals (Weese et al., 2007; Loeffler et al., 2011; WHO, 2017). MRS 
Table 1. Proportion and features of staphylococci species isolated from cats and dogs.

\begin{tabular}{|c|c|c|c|}
\hline No. of staphylococci & $\begin{array}{l}\text { No. of staphylococci by } \\
\text { automated system }\end{array}$ & $\begin{array}{l}\text { No. of MRS by } \\
\text { automated system }\end{array}$ & $\begin{array}{l}\text { No. of confirmed } \\
\text { mec } A \text {-MRS }\end{array}$ \\
\hline \multirow[t]{8}{*}{ Cats $(\mathrm{NO}=24)^{\mathrm{a}}$} & $\mathrm{CoN}=15$ & $\mathrm{CoN}=2$ & $\mathrm{CoN}=2$ \\
\hline & 12; S. felis & 1; S. capitis & $1 ;$ S. capitis \\
\hline & $2 ;$ S. capitis & 1; S. cohnii & $1 ;$ S. cohnii \\
\hline & $1 ;$ S. cohni & & \\
\hline & $\mathrm{CoP}=9$ & $\mathrm{CoP}=2$ & $\mathrm{CoP}=2$ \\
\hline & 5; S. intermedius & $2 ; S$. aureus & $1 ; S$. aureus \\
\hline & $3 ;$ S. aureus & & $1 ;$ S. intermedius \\
\hline & 1; S. schleiferi & & \\
\hline \multirow[t]{4}{*}{$\operatorname{Dogs}(\mathrm{NO}=14)^{\mathrm{b}}$} & $\mathrm{CoN}=9$ & $\mathrm{CoN}=9$ & $\mathrm{CoN}=1$ \\
\hline & $8 ;$ S. sciuri & $8 ;$ S. sciuri & $1 ;$ S. sciuri \\
\hline & $1 ;$ S. lentus & $1 ;$ S. lentus & \\
\hline & $\begin{array}{l}\mathrm{CoP}=5 ; \\
\text { 5; S. aureus }\end{array}$ & $\mathrm{CoP}=0$ & $\mathrm{CoP}=0$ \\
\hline
\end{tabular}

$\left({ }^{a}\right)=1$ clinical and 23 healthy; $\left({ }^{b}\right)=4$ clinical and 10 healthy; $($ No. $)=$ Number, $($ MRS $)=$ methicillin-resistant staphylococci; $($ CoN $)=$ Coagulase-negative; $(\mathrm{CoP})=$ Coagulase-positive.

Table 2. Antimicrobial susceptibility profiling and phenotypes of staphylococci as identified by the Phoenix Automated Identification System $(n=38)$.

\begin{tabular}{lc}
\hline Antibiotic agent & No. and Proportion (\%) \\
\hline Gentamicin & $2^{\mathrm{MRS}}(5.2 \%)$ \\
\hline Imipenem & $13^{\mathrm{MRS}}(34.2 \%)$ \\
\hline Cefoxitin & $13^{\mathrm{MRS}}(34.2 \%)$ \\
\hline Cefotaxime & $12^{\mathrm{MRS}}(6 \%)$ \\
\hline Ampicillin & $33(86.8 \%)$ \\
\hline PenicillinG & $33(86.8 \%)$ \\
\hline Oxacillin & $13^{\mathrm{MRS}}(34.2 \%)$ \\
\hline Amoxicillin-Clavulanate & $13^{\mathrm{MRS}}(34.2 \%)$ \\
\hline Daptomycin & $0(0 \%)$ \\
\hline Trimethoprim- Sulfamethoxazole & $1^{\mathrm{MRS}}(2.6 \%)$ \\
\hline Teicoplanin & $0(0 \%)$ \\
\hline Vancomycin & $2(5.2 \%)$ \\
\hline Clindamycin & $3(7.8 \%)$ \\
\hline Erythromycin & $1^{\mathrm{MRS}-\mathrm{MLS}}(2.6 \%)$ \\
\hline Fusidic acid & $0(0 \%)$ \\
\hline Linezolid & $0(0 \%)$ \\
\hline Mupirocin & $0(0 \%)$ \\
\hline Nitrofurantoin & $0(0 \%)$ \\
\hline Ciprofloxacin & $0(0 \%)$ \\
\hline Moxaifloxacin & $0(90 \%)$ \\
\hline Rifampin & $0(0 \%)$ \\
\hline Tetracycline & $\mathrm{MRS}(2.6 \%)$ \\
\hline & 0 \\
\hline
\end{tabular}

$(\mathrm{MRS})=$ methicillin-resistant staphylococci; $\left(\mathrm{MLS}_{\mathrm{B}}\right)=$ macrolidelincosamide-streptogramin B resistance. of pet's origin was first reported from healthy cats and emerged since after of clinical and nonclinical sources (Walther et al., 2012; Cain, 2013; Somayaji et al., 2016). The methicillin-resistant CoNS are emerging worldwide, including from Africa, and are isolated from various sources, including healthy and clinical pets expressing multidrug resistance patterns and frequent antimicrobial resistance genes, i.e., mec $A$ and $p v l$ genes (Chah et al., 2014; Ibadin et al., 2017; Qekwana et al., 2017; Teixeira, 2019). In the current study, 13\% of pets were mecA-MRS carriers exclusively originated from healthy animals; four mecA-MRS isolated from cats (two of $\mathrm{CoN}$ and CoP staphylococci each) and one mecA-MR S. sciuri isolated from a dog. The CoN group of staphylococci (particularly the $S$. sciuri group) was proposed as an evolutionary precursor of species playing a potential role as a reservoir of important genetic and virulence elements that are frequently reported in $S$. aureus (i.e., mecA gene) (Couto et al., 2003; Zhou et al., 2008; Nemeghaire et al., 2014). Also, the identification of $\mathrm{MLS}_{\mathrm{B}}$ resistance phenotype among CoNS demonstrates the potential spread of critical and cross-multidrug resistance patterns which may become potential gene reservoir for other bacterial organisms. Such strains can be transferred and shared between householders, veterinary personnel, and other companion animals, posing a serious public health and medical concerns (Sing et al., 2008; Couto et al., 2016; Drougka et al., 2016).

Staphylococcus species of veterinary relevance are difficult to identify and characterize due to the underdeveloped diagnostic protocols. The Phoenix automated system has been widely reported as an effective tool for the identifications and antimicrobial susceptibility of staphylococci; however, a few 
species are not distinguishable using this advanced system (Bannoehr et al., 2007). For instance, $S$. pseudintermedius is easily misdiagnosed with $S$. aureus, due to very close phenotypic characteristics requiring molecular methods for definite identification, such matrix assisted laser desorption ionizationtime of flight mass spectrometry (MALDI-TOF MS) or PCR methods (Guardabassi et al., 2017). In the present study and due to limited available resources only the most significant genes associated with clinical complications were screened (i.e., mec $A$ and $p v l$ genes) and further molecular and epidemiological analysis are required.

In conclusion, cats and dogs may harbor various staphylococci species and MRS strains of medical and public health concerns. The reported antimicrobial resistance among the CoNS warrants further attention and continuous monitoring by veterinarians and public health professionals. Preventative measures and antimicrobial stewardship are required to control and minimize the spread of MRS particularly in veterinary and animal medicine in Libya.

\section{Conflict of interest}

The authors declare that there is no conflict of interest. Authors' contribution

Mohamed O. Ahmed designed the study, analyzed data, and wrote the article. Hiam Elnageh and Murad Hiblu collected the samples and data, and performed most of laboratory protocols. Mohamed Abbassi and Yousef Abouzeed contributed to laboratory works and analysis of information. All authors approved the final manuscript.

\section{References}

Ahmed, M.O. and Baptiste, K.E. 2018. Vancomycinresistant enterococci: a review of antimicrobial resistance mechanisms and perspectives of human and animal health. Microb. Drug Resist. 24(5), 590-606.

Ahmed, M.O., Baptiste, K.E., Daw, M.A., Elramalli, A.K., Abouzeed, Y.M. and Petersen, A. 2017. Spa typing and identification of pvl genes of meticillinresistant Staphylococcus aureus isolated from a Libyan hospital in Tripoli. J. Glob. Antimicrob. Resist. 10, 179-181.

Asante, J., Amoako, D.G., Abia, A., Somboro, A.M., Govinden, U., Bester, L.A. and Essack, S.Y. 2020. Review of clinically and pidemiologically relevant coagulase-negative staphylococci in Africa. Microb. Drug Resist. 26(8), 951-970.

Bannoehr, J., Ben Zakour, N.L., Waller, A.S., Guardabassi, L., Thoday, K.L., van den Broek, A.H. and Fitzgerald, J.R. 2007. Population genetic structure of the Staphylococcus intermedius group: insights into agr diversification and the emergence of methicillin-resistant strains. J. Bacteriol. 189(23), 8685-8692.
Cain, C.L. 2013. Antimicrobial resistance in staphylococci in small animals. Vet. Clin. North. Am. Small. Anim. Pract. 43(1), 19-40.

Chah, K.F., Gómez-Sanz, E., Nwanta, J.A., Asadu, B., Agbo, I.C., Lozano, C., Zarazaga, M. and Torres, C. 2014. Methicillin-resistant coagulase-negative staphylococci from healthy dogs in Nsukka, Nigeria. Braz. J. Microbiol. 45(1), 215-220.

Couto, I., Wu, S.W., Tomasz, A. and de Lencastre, H. 2003. Development of methicillin resistance in clinical isolates of Staphylococcus sciuri by transcriptional activation of the mecA homologue native to s. J. Bacteriol. 185(2), 645-653.

Couto, N., Monchique, C., Belas, A., Marques, C., Gama, L.T. and Pomba, C. 2016. Trends and molecular mechanisms of antimicrobial resistance in clinical staphylococci isolated from companion animals over a 16 year period. J. Antimicrob. Chemother. 71(6), 1479-1487.

Davis, J.A., Jackson, C.R., Fedorka-Cray, P.J., Barrett, J.B., Brousse, J.H., Gustafson, J. and Kucher, M. 2014. Carriage of methicillin-resistant staphylococci by healthy companion animals in the US. Lett. Appl. Microbiol. 59(1), 1-8.

Drougka, E., Foka, A., Koutinas, C.K., Jelastopulu, E., Giormezis, N., Farmaki, O., Sarrou, S., Anastassiou, E.D., Petinaki, E. and Spiliopoulou, I. 2016. Interspecies spread of Staphylococcus aureus clones among companion animals and human close contacts in a veterinary teaching hospital. A crosssectional study in Greece. Prev. Vet. Med. 126, 190-198.

Frebourg, N.B., Lefebvre, S., Baert, S. and Lemeland, J.F. 2000. PCR-Based assay for discrimination between invasive and contaminating Staphylococcus epidermidis strains. J. Clin. Microbiol. 38(2), 877880.

Gandolfi-Decristophoris, P., Regula, G., Petrini, O., Zinsstag, J. and Schelling, E. 2013. Prevalence and risk factors for carriage of multi-drug resistant Staphylococci in healthy cats and dogs. J. Vet. Sci. 14(4), 449-456.

Grice, E.A. and Segre, J. A. 2011. The skin microbiome. Nature reviews. Microbiol. 9(4), 244-253.

Guardabassi, L., Damborg, P., Stamm, I., Kopp, P.A., Broens, E.M., Toutain, P.L. and ESCMID Study Group for Veterinary Microbiology. 2017. Diagnostic microbiology in veterinary dermatology: present and future. Vet. Dermatol. 28(1), 146-e30.

Han, J.I., Yang, C.H. and Park, H.M. 2016. Prevalence and risk factors of Staphylococcus spp. carriage among dogs and their owners: a cross-sectional study. Vet. J. 212, 15-21.

Harrison, E.M., Weinert, L.A., Holden, M.T., Welch, J.J., Wilson, K., Morgan, F.J., Harris, S.R., Loeffler, A., Boag, A.K., Peacock, S.J., Paterson, G.K., Waller, A.S., Parkhill, J. and Holmes, M.A. 2014. A 
shared population of epidemic methicillin-resistant Staphylococcus aureus 15 circulates in humans and companion animals. mBio. 5(3), e00985-13.

Ibadin, E.E., Enabulele, I.O. and Muinah, F. 2017. Prevalence of mecA gene among staphylococci from clinical samples of a tertiary hospital in Benin City, Nigeria. Afr. Health Sci. 17(4), 1000-1010.

Jarraud, S., Mougel, C., Thioulouse, J., Lina, G., Meugnier, H., Forey, F., Nesme, X., Etienne, J. and Vandenesch, F. 2002. Relationships between Staphylococcus aureus genetic background, virulence factors, agr groups (alleles), and human disease. Infect. Immun. 70(2), 631-641.

Kaspar, U., von Lützau, A., Schlattmann, A., Roesler, U., Köck, R. and Becker, K. 2018. Zoonotic multidrug-resistant microorganisms among small companion animals in Germany. PloS One. 13(12), e0208364.

Loeffler, A., Pfeiffer, D.U., Lindsay, J.A., Soares Magalhães, R.J. and Lloyd, D.H. 2011. Prevalence of and risk factors for MRSA carriage in companion animals: a survey of dogs, cats and horses. Epidemiol. Infect. 139(7), 1019-1028.

Loncaric, I., Tichy, A., Handler, S., Szostak, M.P., Tickert, M., Diab-Elschahawi, M., Spergser, J. and Künzel, F. 2019. Prevalence of methicillin-resistant Staphylococcus sp. (MRS) in different companion animals and determination of risk factors for colonization with MRS. Antibiotics 8(2), 36.

Ma, G.C., Worthing, K.A., Ward, M.P. and Norris, J.M. 2020. Commensal staphylococci including methicillin-resistant Staphylococcus aureus from dogs and cats in remote new South Wales, Australia. Microb. Ecol. 79(1), 164-174.

Nemeghaire, S., Argudín, M.A., Feßler, A.T., Hauschild, T., Schwarz, S. and Butaye, P. 2014. The ecological importance of the Staphylococcus sciuri species group as a reservoir for resistance and virulence genes. Vet. Microbiol. 171(3-4), 342-356.

Qekwana, D.N., Sebola, D., Oguttu, J.W. and Odoi, A. 2017. Antimicrobial resistance patterns of Staphylococcus species isolated from cats presented at a veterinary academic hospital in South Africa. BMC Vet. Res. 13(1), 286.

Rich, M. 2005. Staphylococci in animals: prevalence, identification and antimicrobial susceptibility, with an emphasis on methicillin-resistant Staphylococcus aureus. Br. J. Biomed. Sci. 62(2), 98-105.

Rossi, C.C., da Silva Dias, I., Muniz, I.M., Lilenbaum, W. and Giambiagi-deMarval, M. 2017. The oral microbiota of domestic cats harbors a wide variety of Staphylococcus species with zoonotic potential. Vet. Microbiol. 201, 136-140.

Ruzauskas, M., Couto, N., Kerziene, S., Siugzdiniene, R., Klimiene, I., Virgailis, M. and Pomba, C. 2015.
Prevalence, species distribution and antimicrobial resistance patterns of methicillin-resistant staphylococci in Lithuanian pet animals. Acta. Vet. Scand. 57(1), 27.

Sing, A., Tuschak, C. and Hörmansdorfer, S. 2008. Methicillin-resistant Staphylococcus aureus in a family and its pet cat. N. Engl. J. Med. 358(11), 1200-1201.

Somayaji, R., Priyantha, M.A., Rubin, J.E. and Church, D. 2016. Human infections due to Staphylococcus pseudintermedius, an emerging zoonosis of canine origin: report of 24 cases. Diagn. Microbiol. Infect. Dis. 85(4), 471-476.

Teixeira, I.M., de Oliveira Ferreira, E. and de Araújo Penna, B. 2019. Dogs as reservoir of methicillin resistant coagulase negative staphylococci strains - a possible neglected risk. Microb. Pathog. 135, 103616.

van Duijkeren, E., Kamphuis, M., van der Mije, I.C., Laarhoven, L.M., Duim, B., Wagenaar, J.A. and Houwers, D.J. 2011. Transmission of methicillinresistant Staphylococcus pseudintermedius between infected dogs and cats and contact pets, humans and the environment in households and veterinary clinics. Vet. Microbiol. 150(3-4), 338-343.

van Duijkeren, E., Wolfhagen, M.J., Heck, M.E. and Wannet, W.J. 2005. Transmission of a pantonvalentine leucocidin-positive, methicillin-resistant Staphylococcus aureus strain between humans and a dog. J. Clin. Microbiol. 43(12), 6209-6211.

Walther, B., Hermes, J., Cuny, C., Wieler, L.H., Vincze, S., Abou Elnaga, Y., Stamm, I., Kopp, P.A., Kohn, B., Witte, W., Jansen, A., Conraths, F.J., Semmler, T., Eckmanns, T. and Lübke-Becker, A. 2012. Sharing more than friendship--nasal colonization with coagulase-positive staphylococci (CPS) and co-habitation aspects of dogs and their owners. PLoS One. 7(4), e35197.

Weese, J.S., Faires, M., Rousseau, J., Bersenas, A.M. and Mathews, K.A. 2007. Cluster of methicillinresistant Staphylococcus aureus colonization in a small animal intensive care unit. J. Am. Vet. Med. Assoc. 231(9), 1361-1364.

WHO. 2017. Publishes list of bacteria for which new antibiotics are urgently needed. Geneva, Switzerland: World Health Organization. Available via http://www.who.int/mediacentre/news/ releases/2017/bacteria-antibiotics-needed/en/

Zhou, Y., Antignac, A., Wu, S.W. and Tomasz, A. 2008. Penicillin-binding proteins and cell wall composition in beta-lactam-sensitive and -resistant strains of Staphylococcus sciuri. J. Bacteriol. 190(2), 508-514. 